\title{
Effects of surface rock fragment characteristics on interrill runoff and erosion of a silty loam soil
}

\author{
Tomás de Figueiredo ${ }^{\mathrm{a}, *}$, Jean Poesen ${ }^{\mathrm{b}}$ \\ ${ }^{a}$ Escola Superior Agrária de Bragança. Apartado 172, 5300 Bragança, Portugal \\ ${ }^{\mathrm{b}}$ Fund for Scientific Research Flanders and Laboratory for Experimental Geomorphology, K.U. Leuven, Redingenstraat 16, 3000 Leuven, \\ Belgium
}

Accepted 22 May 1997

\begin{abstract}
The role played by rock fragments in water erosion has received much attention in recent years. Knowledge of the effects of rock fragment characteristics on interrill erosion is incomplete. Hence, in order to investigate these effects on a small scale, a simulation experiment was conducted in Bragança, Northeast Portugal. The experimental setup consisted of 48 bottom perforated rectangular metal boxes $\left(612 \mathrm{~cm}^{2}\right)$, placed at a $10 \%$ slope, filled with $3.5 \mathrm{~cm}$ of a sieved silty loam soil over $2 \mathrm{~cm}$ of sand, covered by simulated rock fragments and maintained at near saturation. Twelve treatments, four replicates each, were exposed to $240 \mathrm{~mm}$ natural rainfall, comprising selected combinations of rock fragments size (small, medium-gravel range, and large-stone range), shape (rectangular and circular), position (surface, half-embedded and embedded) and cover percentage (17, 30 and $66 \%$ ), and bare soil. Infiltration depth, runoff depth, washed and splashed sediment were repeatedly measured in appropriate collection devices. For bare soil, total wash and total splash were equivalent to $42.2 \mathrm{~g} \mathrm{~m}^{-2}$ and $70.6 \mathrm{~g} \mathrm{~m}^{-2}$, respectively. Infiltration and runoff represented $52 \%$ and $13 \%$ of total rainfall, respectively. Wash has a negative exponential relationship with rock fragment cover (RC). The regression coefficient varies negatively with cumulative precipitation, decreasing significantly after a surface seal is formed (at about $80 \mathrm{~mm}$ cumulative precipitation). The relationship between splash and RC, linear and negative, varies with time, too. Correlation with RC is positive for infiltration depth and negative for runoff depth, both reflecting the seal development with time. The effects of rock fragments size, position and form were tested for $30 \% \mathrm{RC}$. Size has a positive effect on runoff depth, wash and splash, and a negative effect on infiltration depth. The effect of rock fragment size on infiltration, runoff and erosion is more pronounced than that of position. The effect of shape was less significant than that of size and position. (C) 1998 Elsevier Science B.V. All rights reserved.
\end{abstract}

Keywords: Interrill erosion; Rock fragment characteristics; Wash; Splash; Temporal evolution

\footnotetext{
* Corresponding author. Tel.: +351-73-3303201; fax: + 351-73-25405; e-mail: tomasfig@ipb.pt
} 


\section{Introduction}

The presence of rock fragments in soils is a common feature in large areas of the Mediterranean belt where soil erosion is evident and where it also represents a problem (Poesen, 1990). In Northeastern Portugal, shallow soils are dominant and therefore, soil loss contributes to a further decrease in the already low fertility status of these soils (Agroconsultores e Coba, 1991).

Nevertheless, interrill erosion rates, measured in long term field experiments, are generally low, though they might be significant in extreme events (de Figueiredo and Ferreira, 1993). The protective effect of rock fragments is the obvious explanation for these findings, as slopes are moderate to steep, soils are mostly poor in organic matter and present, to a large extent, a very erodible fine earth.

The role played by rock fragments in several soil physical processes, as well as in soil erosion, has been studied intensively in recent years (Poesen and Lavee, 1994; Gras, 1994). Most studies, however, focused on the effect of the cover percentage of rock fragments in erosional or hydrological processes. Little research was dedicated to the effects of other rock fragment characteristics. Laboratory simulations concerning position of rock fragments in soils, as affecting erosion and overland flow, were conducted by Poesen and Ingelmo-Sanchez (1992) and Poesen et al. (1990). The effects of size of rock fragments on overland flow and interrill sediment yield were studied by Poesen and Lavee (1991) and Lavee and Poesen (1991) under indoor rainfall simulation conditions. Also under laboratory conditions, van Wesemael et al. (1994) and van Wesemael et al. (1996) studied the effects of size of rock fragments on soil compaction and soil surface roughness changes during rainfall. These two soil physical aspects control to a certain level the intensity and the extent of rainfall erosion processes.

At present, the dynamics of interrill erosion as affected by rock fragments having different characteristics are poorly understood. This is seen in most erosion models (e.g., RUSLE, WEPP, EUROSEM) which consider rock cover as the only input and disregard, for instance, rock fragment size or shape (Renard et al., 1992; Lane and Nearing, 1989; Morgan et al., 1993).
Therefore, a simulation experiment was conducted to assess the relative importance of the effects of rock fragment characteristics on interrill runoff and erosion. This experiment was conducted under the intermittent precipitation of natural rainfall, allowing close observation of the temporal evolution of the soil response to erosive rains. Since the most eroded soils in the Mediterranean belt are tilled, results of this experiment improve our understanding of how the effects of rock fragments on interrill runoff and erosion of unprotected interrill areas change over time.

The main objectives of this paper are to present and discuss data concerning: (1) the effects of various rock fragment characteristics (i.e., size, position and shape) on the erosional and hydrological response of soils under rainfall; and (2) the changes, observed with time since the beginning of the experiment, of the effect of rock fragment cover on interrill erosion (wash and splash).

\section{Material and methods}

\subsection{Experimental design and setup}

The experimental design consisted of selected combinations of the chosen rock fragment characteristics-cover, size, shape and position (Table 1). Position means the rock fragments were either resting on the soil surface (on top) or embedded in the soil. As depicted in Fig. 1, in the latter case rock fragments were either totally embedded or half-embedded (half of the rock height was embedded). The effect of rock fragment cover (RC) was tested using rectangular medium size rock fragments (gravel range) placed on top of the soil surface, varying from $0 \%$ to $66 \% \mathrm{RC}$. The effects of size, shape and position of rock fragments were tested only for $30 \%$ RC. Each treatment had four replicates.

Bottom perforated metal boxes $(27.1 \mathrm{~cm}$ long, $22.6 \mathrm{~cm}$ wide, $5.5 \mathrm{~cm}$ deep), were filled up with 2 $\mathrm{cm}$ of coarse sand over which $3.5 \mathrm{~cm}$ of the tested fine earth was placed (Fig. 1), except in Treatment 12 , where only coarse sand was used as test material (Table 1). The soil (fine earth) bulk density was made higher at the soil-sand contact $\left(1300 \mathrm{~kg} \mathrm{~m}^{-3}\right)$ and gradually lower up to the surface $\left(1100 \mathrm{~kg} \mathrm{~m}^{-3}\right)$ 
Table 1

Experimental design (rock fragment characteristics, $\mathrm{RC}=$ rock cover)

\begin{tabular}{lllllll}
\hline Treatment & RC $(\%)$ & Size class & Dimensions $(\mathrm{cm})$ & Shape & Position & Material \\
\hline 1 & 0 & - & - & - & - & Soil \\
2 & 16.9 & Medium & $4.8 \times 2.4 \times 1.1$ & Rectangular & On top & Soil \\
3 & 30.1 & Medium & $4.8 \times 2.4 \times 1.1$ & Rectangular & On top & Soil \\
4 & 65.9 & Medium & $4.8 \times 2.4 \times 1.1$ & Rectangular & On top & Soil \\
5 & 30.4 & Small & $2.2 \times 1.2 \times 1.1$ & Rectangular & On top & Soil \\
6 & 30.1 & Large & $9.6 \times 4.8 \times 1.1$ & Rectangular & On top & Soil \\
7 & 28.7 & Small & $\varnothing 2.0 \times 1.1$ & Circular & On top & Soil \\
8 & 28.7 & Medium & $\varnothing 4.0 \times 1.2$ & Circular & On top & Soil \\
$9^{\mathrm{a}}$ & 30.1 & Medium & $4.8 \times 2.4 \times 1.1$ & Rectangular & Half-embedded & Soil \\
10 & 30.1 & Medium & $4.8 \times 2.4 \times 1.1$ & Rectangular & Embedded & Soil \\
11 & 28.7 & Medium & $\varnothing 4.0 \times 1.2$ & Circular & Embedded & Soil \\
$12^{\mathrm{a}}$ & 30.1 & Medium & $4.8 \times 2.4 \times 1.1$ & Rectangular & On top & Sand \\
\hline
\end{tabular}

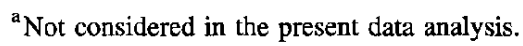

(Fig. 1). Embedded rock fragments were placed without compression of the soil underneath and, for all treatments, rock fragments were distributed in a 'running bond' pattern (Fig. 1). Before exposition to outdoor conditions, the soil in the boxes was saturated for $24 \mathrm{~h}$.

A metallic splash board, $10 \mathrm{~cm}$ height and 27.1 $\mathrm{cm}$ long, with a collector for splashed material in its bottom, was placed along the right side of each box (Fig. 1). The boxes were inserted into metal trays and leaned for $10 \%$ slope. A small metallic bridge connected the front edge of the soil box to the runoff water and sediment collector. The collector consisted of a plastic bag tied to and resting inside a second box, similar to the soil box, covered by a polystyrene plate. A rigid plastic tube was inserted through a hole in the back part of the tray and fixed vertically so that its top coincided with the rear edge base of the soil box. The infiltration water was evacuated through this tube into a glass container (about 1 1) bypassing a flexible plastic pipe, since during the experiment the trays were filled with water, added once or twice a day. This procedure ensured 'near' saturation conditions of the soil in the box. The experimental apparatus was adapted, with important modifications, from that used by Free (1952).

The soil used in the experiment (the same for all but Treatment 12) was sampled in the Douro Region, where erosion plots, installed in steep slope vineyards, provide data on runoff and interrill and rill soil loss (de Figueiredo and Ferreira, 1993). The soil, classified according to FAO as very gravelly schist derived dystric Anthrosol (FAO/UNESCO, 1988), contains $5 \%$ clay, $41 \%$ silt and $50 \%$ fine sand and about $60 \%$ by mass of rock fragments, and low organic matter content $(0.5 \%)$. The sampled soil was air-dried and sieved $(2 \mathrm{~mm})$ and only fine earth was used as test material.

Simulated rock fragments of rectangular shape consisted of ceramic pieces regularly cut at three sizes (small, medium-gravel range, and largestone range) (see Table 1). Circular shape rock fragments (small and medium sizes-gravel range, Table 1) were simulated using rigid plastic rings filled with melted paraffin mixed with small lead pieces. This procedure was followed in order to achieve densities comparable to those of rock fragments (about 2400 $\mathrm{kg} \mathrm{m}^{-3}$ ).

The boxes were randomly placed in groups of six over wood frames $1.2 \mathrm{~m}$ above ground (Figs. 1 and 2), and exposed to natural weather conditions from May to November 1994, at Quinta de Santa Apolónia, Escola Superior Agrária de Bragança, Portugal $\left(42^{\circ} \mathrm{N}\right.$, $7^{\circ} \mathrm{W}$ and $670 \mathrm{~m}$ elevation). In order to avoid interference with plants, a weed control treatment was applied to all boxes.

The climatic regime in the test site is Mediterranean, with an average annual temperature of $12^{\circ} \mathrm{C}$ and $800 \mathrm{~mm}$ of annual average precipitation. Summers are hot and dry with average monthly temperature above $20^{\circ} \mathrm{C}$ (July and August). Less than $10 \%$ of the total annual rainfall occurs from July to Septem- 

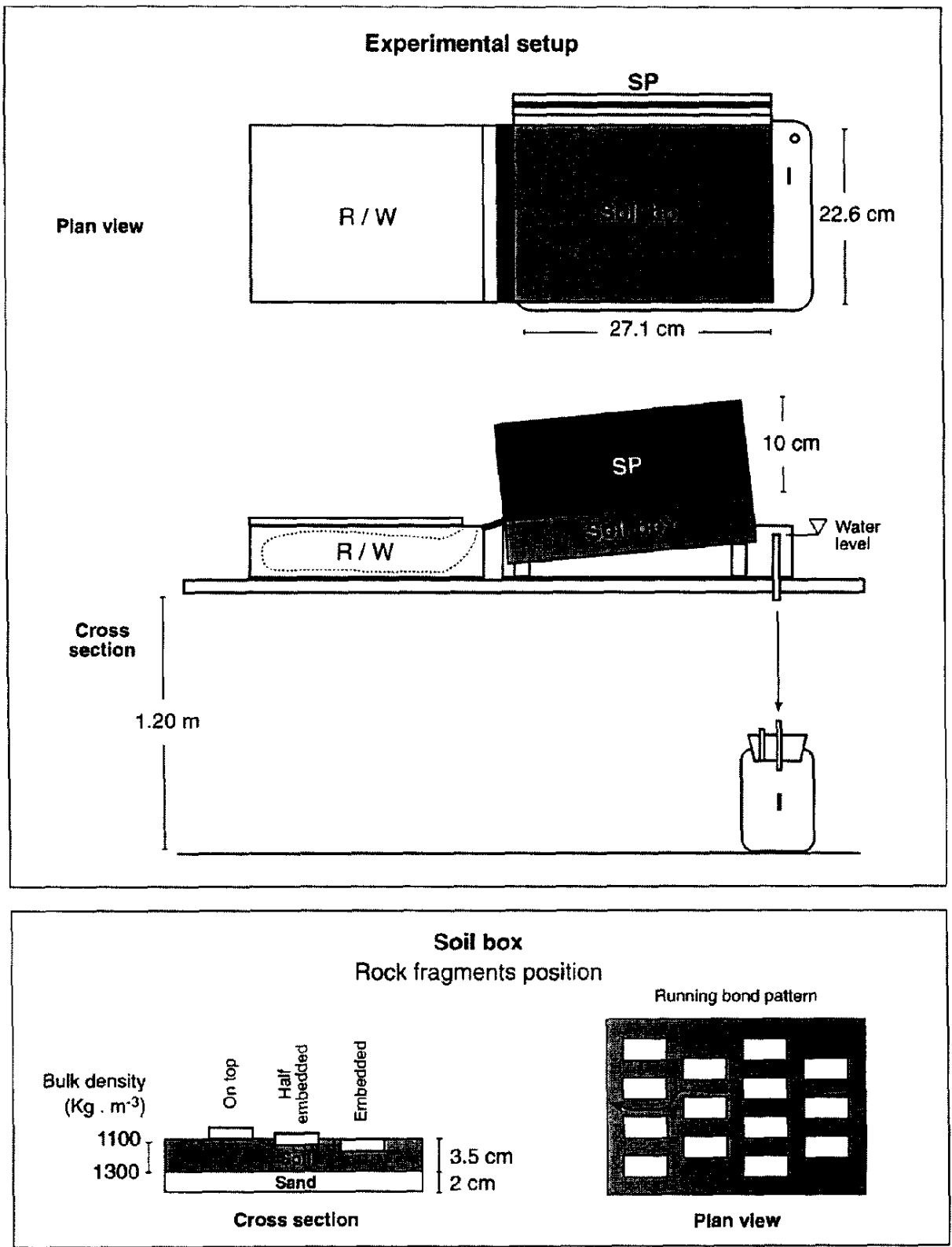

Fig. 1. Experimental setup: I-Infiltration; R-Runoff; W-Wash; SP-Splash board.

ber. During the measurement period, $240 \mathrm{~mm}$ of rain was recorded.

\subsection{Data collection and handling}

During the experimental period, either the water (runoff) and sediment (wash) trapped in the frontal collector or the sediment captured by the lateral splash board (splash) were measured five times. Each of the measurements was performed after a period of precipitation. Due to the time required to accomplish all collection procedures, splash and runoff plus wash could not be measured in the same 
dates. Infiltration water evacuated to the glass container was measured more frequently, normally after each rainfall. Infiltration data collected were grouped in precipitation periods coinciding with those of runoff plus wash collection. A local station gathered meteorological data during the experimental period.

Considerable runoff and wash data were lost, mainly because the collector was not very easy to handle; the plastic bag sometimes leaked, and systematic handling problems led either to loss of water or to incorrect weighing of sediment due to difficulties in emptying and cleaning. In all these cases, the measurements were withdrawn, and were considered as missing values.

Water data collected were converted in infiltration and runoff depths (mm), and washed sediment (wash) and splashed sediment (splash) were expressed in mass per unit area $\left(\mathrm{g} \mathrm{m}^{-2}\right)$, with appropriate calculations and corrections due to the experimental apparatus design.

Missing values, frequent in number, not only biased averages and consequently data interpretations, but also hampered some statistical analysis (e.g., ANOVA and mean separation techniques, Steel and Torrie, 1980). So, appropriate statistical tech- niques were applied to rebuild data series for events where missing values exceeded $10 \%$ of data, as in the case of Event 1 (runoff and wash), Event 5 (wash) and Global results (runoff and wash).

Global results, as they are named hereafter, correspond to the sum of all event values of each measured variable. For each event and for global results some indices were calculated, namely: (i) infiltration coefficient (infiltration depth/precipitation depth, in $\%$ ), (ii) runoff coefficient (runoff depth/precipitation depth, in \%), (iii) splash water coefficient (100 less the sum of infiltration and runoff coefficients), (iv) wash per unit rainfall ( $\mathrm{g}$ sediment $\mathrm{m}^{-2} \mathrm{~mm}^{-1}$ precipitation), (v) splash per unit rainfall ( $\mathrm{g}$ sediment $\mathrm{m}^{-2} \mathrm{~mm}^{-1}$ precipitation), (vi) sediment concentration in runoff (washed sediment/runoff water, in $\mathrm{g}$ $\mathrm{l}^{-1}$ ), (vi) sediment concentration in splash (splashed sediment/splash water, in $\mathrm{g}^{-1}$ ). Relative values for all data were also calculated, using the bare soil treatment as the reference values (treatment value/bare soil value).

For the present paper, data from Treatment 9 (half-embedded rock fragments) and Treatment 12 (sand as test material) were not considered in the analysis and discussion of results (Table 1), partly

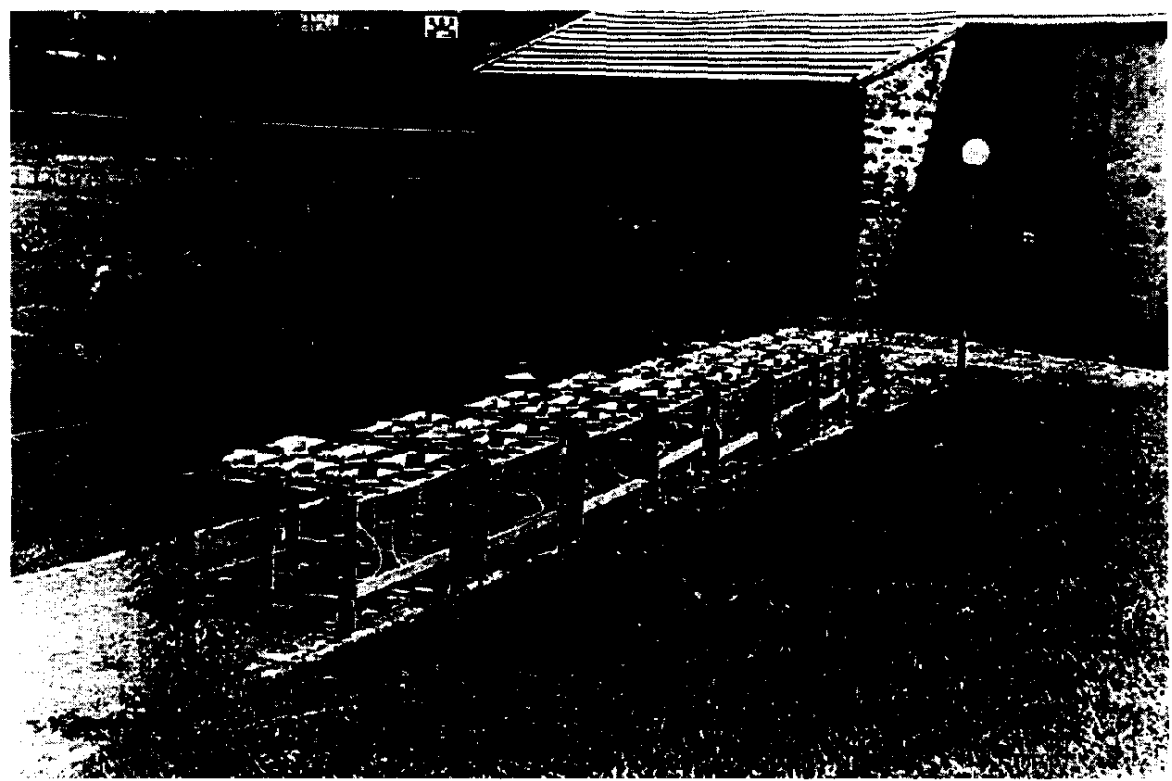

Fig. 2. General view of the experimental setup 
because of statistical analysis constraints as explained below (see Section 2.4), and partly because the results fall out of the scope of this paper.

\subsection{Sources of error}

Due to the nature of the experimental design and to changes in the soil boxes during the observation period, some sources of error could be identified.

A decrease in soil depth was observed during the experiment, due either to soil loss or, in a far more important way, to structural degradation and compaction (as described by van Wesemael et al., 1994). Thus, runoff water accumulation and infiltration were certainly enhanced in the lower part of soil boxes. Wash was probably also affected by soil depth decrease during the experiment.

The splash collected represents almost all the sediment splashed out from the soil boxes. Calculations according to formulae provided by Poesen and Savat (1981), Savat and Poesen (1981), Poesen and Torri (1988), and also according to the ballistics' equations, showed that the experimental error is at most about $3.5 \%$.

\subsection{Statistical analysis}

Statistical analysis comprised: (i) the calculations of statistics of all variables measured and indexes calculated, (ii) the analysis of variance to test the significance of effects involved normally followed by mean separation techniques, and (iii) regression analysis, either linear or non-linear.

The experiment was designed, for the sake of material and work economy, as an incomplete factorial. Thus, some factor combinations were not tested. Hence, the analysis of variance testing the significance of size, shape and position effects only considered two levels for rock fragments position (on top and totally embedded), and not three as originally tested, because this was the minimum factorial combination allowing the analysis to be performed. Furthermore, the complete ANOVA table considering the effects of size, position and shape of rock fragments, and their interactions, on the output variables of the experiment, could not be calculated due to lack of some factorial combinations. The ANOVA tables calculated consider the single and additive
Table 2

Effects of size, position and shape of rock fragments and their interaction on wash global results, expressed as relative values (ANOVA headings: $d f$-degrees of freedom, MS-mean squares, $P$-probability, $R^{2}$-determination coefficient)

\begin{tabular}{lrlll}
\hline Source & $d f$ & MS & $P$ & $R^{2}$ \\
\hline Size & 2 & 0.1840 & $0.0000^{* * *}$ & 0.576 \\
Error & 24 & 0.0113 & & \\
Size & 2 & 0.0909 & $0.0010^{* * *}$ & 0.656 \\
Position & 1 & 0.0514 & $0.0297^{* *}$ & \\
Error & 23 & 0.0096 & & \\
Size & 2 & 0.0898 & $0.0014^{* * *}$ & 0.658 \\
Position & 1 & 0.0503 & $0.0348^{* *}$ & \\
Shape & 1 & 0.0013 & $0.7225 \mathrm{~ns}$ & \\
Error & 22 & 0.0099 & & \\
Size & 2 & 0.1040 & $0.0000^{* * *}$ & 0.855 \\
Position & 1 & 0.0657 & $0.0013^{* * *}$ & \\
Shape & 1 & 0.0003 & $0.7895 \mathrm{~ns}$ & \\
Size vs, position vs. shape & 2 & 0.0622 & $0.0002^{* * *}$ & \\
Error & 20 & 0.0047 & & \\
\hline
\end{tabular}

Significance of effects: non-significant (ns); significant at $P<0.10$ $\left({ }^{*}\right), P<0.05\left({ }^{* *}\right)$ and $P<0.01\left({ }^{* * *}\right)$.

effects of size, position and shape of rock fragments and one of their interactions (see Table 2).

In regression analysis, all exponential fits found were obtained by linear regression (least squares) of transformed variables.

\section{Results and discussion}

\subsection{Global results}

Global results showed statistically non-significant differences among replicates. These findings suggest that results may be interpreted disregarding the replicate effect.

Coefficients of variation ( $\mathrm{CV}=$ standard deviation/mean, in \%), calculated for each treatment, were highest for runoff (average $\mathrm{CV}$ of $21 \%$ ), intermediate for wash and splash (10\% and $13 \%$, respectively), and lowest for infiltration (4\%).

\subsubsection{Rock cover effect}

3.1.1.1. Water partitioning in infiltration and runoff. For bare soil, $52 \%$ of total precipitation falling over the boxes during the experimental period infiltrated 


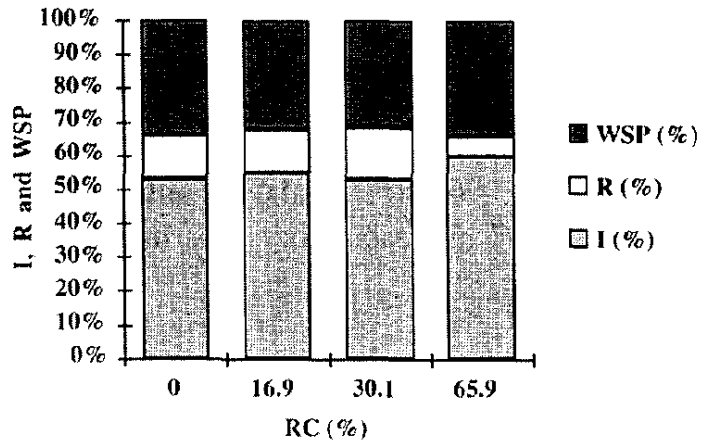

Fig. 3. Effect of rock cover (RC, \%, rectangular, medium size, resting on top soil rock fragments) on rainwater partitioning: global results for infiltration coefficient $(1)$, runoff coefficient $(R)$ and splash water coefficient (WSP)

and $13 \%$ has been collected as runoff water. The remaining water was splashed out of the boxes.

Similar results for medium size, rectangular rock fragments resting on top of the soil surface show that infiltration depth increased as rock cover increased. Runoff depth decreased as rock cover increased. The trend of rainwater partitioning, as affected by rock cover (RC), is shown in Fig. 3 and generally agrees with published data concerning rock fragments placed on top of the soil surface. Poesen (1992) discussed the relationship between runoff depth and rock cover. He explained that when rock fragments rest on top of the soil surface, part of the rock flow and part of the Hortonian overland flow generated in the sealed bare soil area between rock fragments, can be absorbed by the unsealed soil surface below rock fragments. The increase of rock cover directly increases the unsealed surface below rock fragments, thus, allowing an increase in infiltration.

Regression analysis applied to relative infiltration (Irel), relative runoff (Rrel) and relative splash water (WSPrel) depths, confirmed the trends mentioned above (four RC levels, four replicates each, expressed in \%):

$$
\text { Irel }=0.9956+0.0022 \mathrm{RC} \quad n=14 \quad r=0.791^{* * *}
$$

Rrel $=1.1602-0.0078 \mathrm{RC}$

$n=16 \quad r=-0.581^{* *}$

$\mathrm{WSPrel}=0.9732+0.0003 \mathrm{RC}$

$n=14 \quad r=0.109$ ns
The intercepts of the regression lines are not significantly different from 1 . This means that the output of the regression functions is a relative value not statistically different from 1, for bare soil $(\mathrm{RC}=0)$.

The sum of the slopes of the infiltration and runoff regression lines shows that splash water is not affected by $\mathrm{RC}$ (see also Fig. 3). This result is also indicated by an insignificant correlation coefficient between these last two variables.

The effect of RC on runoff is much less evident than that on infiltration, as can be seen when comparing the correlation coefficient of the infiltration vs. $\mathrm{RC}$ regression with the one of the runoff vs. RC regression (see Eqs. (1) and (2)). Furthermore, runoff increased $22 \%$ from 0 to $30 \% \mathrm{RC}$, but a sharp reduction of runoff was found for $\mathrm{RC}=66 \%(51 \%$ of bare soil runoff; Table 3).

The runoff results can be explained by the tortuosity of runoff paths. Up to $\mathrm{RC}=30 \%$, straight flow lines remain possible in the bare interrill area between rock fragments. In that situation, runoff water either generated in the uncovered soil surface or added by rock flow, tends to flow more efficiently. For higher RC, flow becomes necessarily tortuous and thus, runoff rates are reduced because of increased opportunity for infiltration.

3.1.1.2. Wash and splash. Global results for bare soil are equivalent to $42.2 \mathrm{~g}$ sediment $\mathrm{m}^{-2}$ for wash and $70.6 \mathrm{~g}$ sediment $\mathrm{m}^{-2}$ for splash. Relative wash and splash results, corresponding to the cover percentages tested, are shown in Table 3.

A negative relationship was found between RC and either wash or splash. Yet, the shape of these two relationships is not the same, as can be seen in Fig. 4.

Extensive literature quotations report that a negative exponential fit best describes the effect of $\mathrm{RC}$ on wash (four RC levels, four replicates each, expressed in \%) (Fig. 3):

$$
\begin{aligned}
& \text { Wrel }=1.180 \exp (-0.0281 \mathrm{RC}) \\
& n=16 \quad r=-0.966^{* * *}
\end{aligned}
$$

Intercept is not significantly different from 1 .

The exponent of the regression function represents the intensity of the factor ( $\mathrm{RC})$ in the process 
and can be compared with published data, regardless of the soil material studied. Poesen et al. (1990) showed experimentally that this factor depends on soil characteristics (namely, the fine earth structure), or on rock fragments position (on top or embedded). Poesen (1992) indicated exponent values of -0.040 (rock fragments resting on soil surface) and -0.020 (rock fragments partially embedded). de Lima (1990) assembling data from several sources (Box, 1981; Meyer et al., 1972; Simanton et al., 1984), reported exponents from -0.030 to -0.053 , and obtained a value of -0.037 in a laboratory experiment with a

Table 3

Mean global results (in relative values-treatment valuc/bare soil value): infiltration (Irel), runoff (Rrel), splashed water (WSPrel), wash (Wrel) and splash (SPrel)

\begin{tabular}{llllc}
\hline (a) Effect RC (medium size, rectangular, on top) & & & \\
\hline Parameter & Bare soil & $\mathrm{RC}=17 \%$ & $\mathrm{RC}=30 \%$ & $\mathrm{RC}=66 \%$ \\
\hline Irel & 1.00 & 1.05 & 1.02 & 1.15 \\
Rrel & 1.00 & 1.02 & 1.22 & 0.51 \\
WSPrel & 1.00 & 0.97 & 0.94 & 1.01 \\
Wrel & 1.00 & 0.76 & 0.65 & 0.17 \\
SPrel & 1.00 & 0.68 & 0.57 & 0.26
\end{tabular}

(b) Effect size ( $\mathrm{RC}=30 \%$, on top) (crossed with shape)

\begin{tabular}{|c|c|c|c|c|}
\hline \multirow[t]{2}{*}{ Parameter } & \multirow[t]{2}{*}{ Shape } & \multicolumn{3}{|l|}{ Size } \\
\hline & & Small & Medium & Large \\
\hline Irel & Rectangular & 1.10 & 1.02 & 1.07 \\
\hline Rrel & & 0.68 & 1.22 & 0.98 \\
\hline WSPrel & & 1.02 & 0.94 & 0.96 \\
\hline Wrel & & 0.37 & 0.65 & 0.50 \\
\hline SPrel & & 0.44 & 0.57 & 0.52 \\
\hline Irel & Circular & 1.09 & 1.01 & - \\
\hline Rrel & & 0.98 & 1.14 & - \\
\hline WSPrel & & 0.93 & 0.98 & - \\
\hline Wrel & & 0.33 & 0.47 & - \\
\hline SPel & & 0.40 & 0.52 & - \\
\hline \multicolumn{5}{|c|}{ (c) Effect shape $(\mathrm{RC}=30 \%)$ (crossed with size and position) } \\
\hline \multirow[t]{2}{*}{ Parameter } & \multirow[t]{2}{*}{ Size } & \multirow[t]{2}{*}{ Position } & \multicolumn{2}{|l|}{ Shape } \\
\hline & & & Rectangular & Circular \\
\hline Irel & Small & On top & 1.10 & 1.09 \\
\hline Rrel & & & 0.68 & 0.98 \\
\hline WSPrel & & & 1.02 & 0.93 \\
\hline Wrel & & & 0.37 & 0.33 \\
\hline SPrel & & & 0.44 & 0.40 \\
\hline Irel & Medium & On top & 1.02 & 1.01 \\
\hline Rrel & & & 1.22 & 1.14 \\
\hline WSPrel & & & 0.94 & 0.98 \\
\hline Wrel & & & 0.65 & 0.47 \\
\hline SPrel & & & 0.57 & 0.52 \\
\hline Irel & & Embedded & 1.08 & 1.06 \\
\hline Rrel & & & 1.31 & 1.29 \\
\hline WSPrel & & & 0.82 & 0.85 \\
\hline Wrel & & & 0.60 & 0.79 \\
\hline SPel & & & 0.58 & 0.59 \\
\hline
\end{tabular}




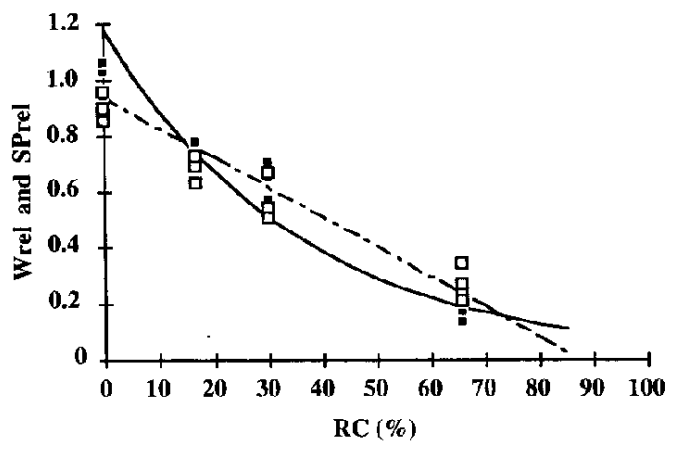

Fig. 4. Effect of rock cover (RC) on wash (Wrel-black squares) and splash (SPrel-white squares): global results in relative values (trcatment value/bare soil value) (rectangular, medium size, resting on top soil rock fragments).

soil from Southern Portugal. Wischmeier and Smith (1978) assumed an exponent of -0.032 when describing the effect of a mulch cover on interrill and rill-erosion.

The exponent of the regression function obtained (Eq. (4)) falls in the lower range of values found in literature. Homogeneous simulated rock fragments used in this experiment (all with the same size and shape in each treatment) may explain differences found. In fact, rock fragments in field soil have different sizes and shapes and are randomly distributed, which strongly contributes to the generation of reticular overland flow (Baird et al., 1992). This effect is more pronounced for higher RC values. So, the rates of variation of wash with $\mathrm{RC}$ are higher in field soils than those found with simulated rock fragments with a single size and shape.

A negative relationship between splash and \% RC was also found (four $\mathrm{RC}$ levels, four replicates each, expressed in \%) (Fig. 4):

SPrel $=0.9390-0.0107 \mathrm{RC}$

$n=14 \quad r=-0.921^{* *}$

A higher correlation coefficient was obtained when fitting an exponential curve through the SPrel data $(-0.963$ against -0.921$)$. Nevertheless, as proposed by Poesen (1992), a linear fit seems to better represent processes involved, because an exponential curve estimates positive splash values for $100 \% \mathrm{RC}$, a physically impossible situation. On the contrary, according to results of linear fitting, splash would cease at $\mathbf{8 8 \%} \mathrm{RC}$, a situation that can be explained either by extremely short distances between rock fragments (eventually smaller than raindrop diameter) or by the impossibility of splash measurements with the experimental setup when the free ejection of splashed particles is hampered by rock fragment height.

\subsubsection{Other effects: size, shape and position of rock fragments}

The effects of size, shape and position were tested for $\mathrm{RC}=30 \%$. The effect of position was tested for medium size rock fragments.

\subsubsection{Rock fragment size effect. Size of rock frag-} ments has a negative effect on global infiltration (Irel) and a positive one on global runoff (Rrel) (Table 3). These findings corroborate results from laboratory experiments (Poesen and Lavee, 1991), which were explained by these authors as being due to rock water flow and continuity of this runoff on the uncovered surface. Rock water flow is lower for smaller rock fragments, leading to higher infiltration rates and lower runoff rates.

The effect of size of rock fragments on both splash (SPrel) and wash (Wrel) is positive (Table 3), with an important increase from small to medium size rock fragments and a much less important decrease from medium to large rock fragments. Apart from the $66 \% \mathrm{RC}$ treatment, the results of wash and splash from soil surfaces covered by small rock fragments were the lowest found in the experiment (for circular rock fragments, $40 \%$ of bare soil results for splash and $33 \%$ for wash). These results show the importance of small rock fragments in protecting soil from water erosion. The general trend found agrees with that reported by Poesen and Lavee (1991), even though the small rock fragments of their experiments were larger than those tested in our experiment. The effect of rock fragment size was also found to be important with respect to soil compaction and soil surface roughness evolution during rainfall (van Wesemael et al., 1994, 1996).

The reason for an increase in splash with rock fragment size (from small to medium) is explained by the fact that interception of splashed sediment by rock fragments does not allow splashed particles to reach the splash board. As the uncovered surface is 
more discontinuous in the case of small rock fragments, the probability of interception becomes higher. This trend was found both for rectangular and for circular rock fragments.

The positive effect of rock fragment size on wash can be explained by several mechanisms. Runoff production is lowest for the smallest rock fragments and its velocity is less than that for medium size rock fragments, because of the tortuosity of flow paths, which leads to an increased overland flow discontinuity (Lavee and Poesen, 1991). So, transport capacity of overland flow is more limited for small rock fragments.

\subsubsection{Rock fragment shape effect. The rock frag-} ment shape effect is not perceptible for infiltration (Table 3). In fact, for all comparable treatments (small and medium size rock fragments on top and embedded medium size rock fragments), infiltration is $1 \%$ less for circular rock fragments than that for the rectangular ones.

Differences concerning runoff and splash water are affected by differences between shapes (Table 3 ). For medium size rock fragments, the proportion of runoff is slightly less for circular shapes. Runoff differences between the two shapes are negligible for embedded rock fragments. For these rock fragment characteristics, splash water is slightly higher for circular shapes (4\% or less). For small rock fragments, runoff is lower and splash water is higher in rectangular shapes as compared to circular ones.

As embedded rock fragments do not contribute to macro-roughness of the soil surface, thus, do not limit overland flow, runoff results show negligible differences between the two shapes tested. The effect of shape of rock fragments on macro-roughness and on the form of overland flow paths was more pronounced for rock fragments resting on top of the soil surface than in the case of embedded rock fragments. One can empirically predict that circular forms create conditions for enhanced overland flow, as the drag coefficient is certainly smaller than for rectangular rock fragments. Runoff results agree with this prediction for small rock fragments but not for medium size ones. These findings may be explained by the larger number of overland flow paths in the case of small rock fragments, enhancing the effect of shape of rock fragments on runoff. In the case of medium size rock fragments, the number of overland flow paths is much lower, hence, differences between runoff results for the two shapes are negligible.

For small and medium size rock fragments resting on top of the soil surface, circular rock fragments generate less wash and splash than the rectangular ones (Table 3). For medium size embedded rock fragments, circular shapes generate more wash and slightly more splash than the rectangular ones. These findings stress the complex effect of shape observed, which, in any case, is not significant.

\subsubsection{Rock fragment position effect. Total runoff} was higher for embedded rock fragments compared to total runoff for rock fragments placed on top of the soil surface. The highest runoff values of all treatments were found for embedded rock fragments. Poesen and Lavee (1991) explained that interrill areas covered by embedded rock fragments do not limit overland flow, because of the low macroroughness of these surfaces, and that overland flow is actually promoted, due to water flow generated on the impermeable rock fragment surfaces. The effect of rock fragment position on infiltration was significantly less than that on runoff, though the same trend was found (Table 3). When the calculations of the proportions of runoff and infiltration do not account for splash water (runoff + infiltration $=100$ ), then very small differences are found between embedded and on top rock fragments.

Treatments with embedded rock fragments produced more soil splash than treatments with on top rock fragments, especially for circular rock fragments (Table 3). This is explained by the fact that there is virtually no splash interception for embedded rock fragments and that detached particles deposited on the covered surface can again be removed by splash. On the contrary, on top rock fragments intercept splashed soil particles, thus, reducing sediment exported by splash. This trend was not so clear in the case of rectangular rock fragments.

For wash, trends were opposite when comparing rectangular and circular rock fragments (Table 3). In the case of circular rock fragments, wash was higher for the embedded rock fragments than for the on top ones. This is explained by the smoother interrill surface prevailing for embedded rock fragments, 
which does not reduce overland flow velocity, thus, leading to a more efficient sediment transport. On the contrary, in the case of rectangular rock fragments, wash was lower for the embedded when compared to the on top rock fragments.

\subsubsection{Relative importance of effects. Analysis of} variance was performed to test the relative importance of the effects of the tested rock fragment characteristics on global infiltration, runoff, splash water, wash and splash results. As explained before (see Section 2), for the effect of position, only two positions were considered. These corresponded to the extreme situations of (1) resting on the soil surface (on top) and (2) totally embedded rock fragments (Fig. 1). Due to the incomplete factorial design, it was only possible to consider one interaction in the ANOVA calculations, namely, size vs. position vs. shape of rock fragments. Thus, discussion of results is limited to the single effects of size, shape and position of rock fragments and the interaction mentioned. Furthermore, for the same reason, statistical comparison of treatments for significant effects was not performed. An example of the ANOVA tables calculated is given in Table 2.

Data shown in Table 4, extracted from Table 2, correspond to the statistical significance of the overall effects of size, shape and position of rock fragments and their interaction, on global results. Shape of rock fragments does not show any significant effect on any of the measured variables. On the

Table 4

Significance of the effects of size, position and shape of rock fragments on global results, expressed in relative values (treatment/bare soil), of infiltration (Irel), runoff (Rrel), splash water (WSPrel), wash (Wrel) and splash (SPrel): probability $(P)$ valucs extracted from the ANOVA tables calculated

\begin{tabular}{llll}
\hline Variable & \multicolumn{3}{l}{ Rock fragments characteristic } \\
\cline { 2 - 3 } & \multicolumn{1}{l}{ Size } & \multicolumn{1}{l}{ Position } & Shape \\
\cline { 2 - 3 } & \multicolumn{1}{l}{$P$ and significance } \\
\hline Ircl & $0.0455^{* *}$ & $0.0696^{*}$ & $0.6330 \mathrm{~ns}$ \\
Rrel & $0.0184^{* *}$ & $0.3430 \mathrm{~ns}$ & $0.6935 \mathrm{~ns}$ \\
WSPrel & $0.7371^{\mathrm{ns}}$ & $0.0464^{* *}$ & $0.5501 \mathrm{~ns}$ \\
Wrel & $0.0000^{* * *}$ & $0.0013^{* *}$ & $0.7895 \mathrm{~ns}$ \\
SPrel & $0.0082^{* * *}$ & $0.3537 \mathrm{~ns}$ & $0.6823 \mathrm{~ns}$ \\
\hline
\end{tabular}

Significance of effects: non-significant (ns); significant at $P<0.10$ $\left({ }^{*}\right), P<0.05\left({ }^{*}\right)$ and $P<0.01\left({ }^{* *}\right)$.

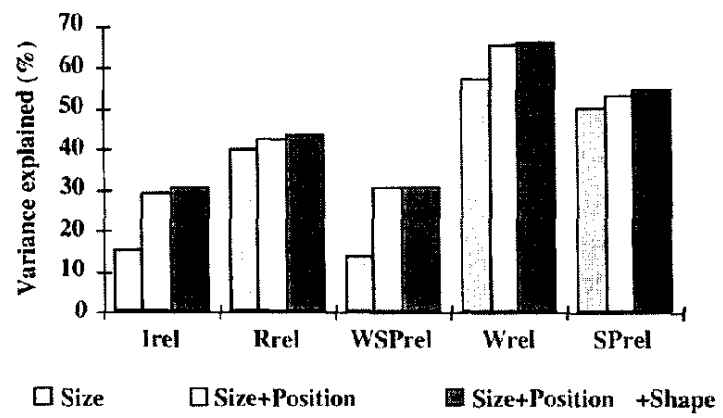

Fig. 5. Effects of size, shape and position of rock fragments in rainwater partitioning and erosion: global results variance explained by these effects. Infiltration (Irel), runoff (Rrel), splash water (WSPrel), wash (Wrel) and splash (SPrel) are expressed in relative values-treatment value/bare soil value.

contrary, size significantly affects all variables but splash water (WSP). Position of rock fragments does not significantly affect runoff and splash.

Splash and runoff were only significantly affected by the size of rock fragments, though this effect was less significant for runoff (Table 4). For wash, a highly significant effect of the size of rock fragments was found, together with a less significant effect of position of rock fragments. The same trend was also observed for infiltration. Splash water was only significantly affected by the position of rock fragments.

The determination coefficients $\left(R^{2}\right)$ calculated in the ANOVA tables (see Table 2), represent the contribution of each effect successively incorporated in the analysis, to the explained data variance. Fig. 5 depicts the single and combined effects of rock fragments size, position and shape on the explained variance of infiltration (Irel), runoff (Rrel), splash water (WSPrel), wash (Wrel) and splash (SPrel) results. The most important contribution, for all measured variables, is due to size of rock fragments. A considerable increase in the explained variance of results is obtained when the effect of position is added up to the analysis. This is especially the case for infiltration and splashed water. A very small increase in the explained variance of results is provided by the consideration of shape in the analysis, which is almost nil for splashed water.

As also shown in Fig. 5, global variance of results explained by these effects (without considering interactions) accounts for slightly more than $60 \%$ in the case of wash, but it accounts for only $30 \%$ in the 
case of infiltration and splash water. These results draw the attention to the complex interactions between factors (not all screened in the analysis performed) which certainly contribute to the non-explained data variance. For all variables but wash, these interactions are paired ones, since the interaction included in the ANOVA tables (size vs. position vs. shape) is not significant. For wash, not only this interaction is significant but also its contribution to explain data variance is important (see $R^{2}$ in Table 2 ). Therefore, results indicate that the effects of the tested rock fragment characteristics on the measured variables are not strictly independent.

\subsection{Temporal evolution of results: the effect of rock cover on wash and splash}

The temporal evolution of results refers to data collected during the experiment. The following discussion focuses on relative values of wash and splash calculated for each data collection.

As stated before, wash followed a negative exponential relationship with $\mathrm{RC}$. The coefficient of the exponential function tended to decrease during the course of the experiment (Table 5). Fig. 6 compares the relationship for the first event with that for the end of the experiment. The same trend was found for splash (Table 5 and Fig. 7), though the shape of the relationship with $\mathrm{RC}$ is linear.

Wash results showed that until the third event (about $80 \mathrm{~mm}$ of cumulative precipitation) the re-

\section{Table 5}

Temporal evolution of the regression parameters of the relationships between wash and $\mathrm{RC}$ (Wrel $=a \exp (b \mathrm{RC})$, where Wrel is the Wash relative value) and splash and $\mathrm{RC}$ (SPrel $=a+b \mathrm{RC}$, where SPrel is the Splash relative value)

\begin{tabular}{lllll}
\hline Event & \multicolumn{2}{l}{ Wash } & \multicolumn{3}{l}{ Splash } \\
\cline { 2 - 3 } \cline { 5 - 6 } & $b$ & & \multicolumn{1}{l}{$b$} & $r$ \\
\hline 1 & $-0.0389 \mathrm{a}$ & $0.968^{* * *}$ & $-0.0111 \mathrm{a}$ & $0.960^{* * *}$ \\
2 & $-0.0359 \mathrm{ac}$ & $0.931^{* * *}$ & $-0.0113 \mathrm{a}$ & $0.774^{* * *}$ \\
3 & $-0.0284 \mathrm{bc}$ & $0.948^{* * *}$ & $-0.0105 \mathrm{a}$ & $0.751^{* * *}$ \\
4 & $-0.0197 \mathrm{bd}$ & $0.804^{* * *}$ & $-0.0068 \mathrm{a}$ & $0.545^{* *}$ \\
5 & $-0.0182 \mathrm{~b}$ & $0.661^{* *}$ & $-0.0069 \mathrm{a}$ & $0.326 \mathrm{~ns}$ \\
\hline
\end{tabular}

Values of regression slopes ( $b$ columns) followed by the same letter are not significantly different from each other $(P<0.05)$; significance of the correlation coefficients $(r)$; non-significant (ns); significant at $P<0.10\left(^{*}\right), P<0.05\left(^{* *}\right), P<0.01\left(^{* * *}\right)$.

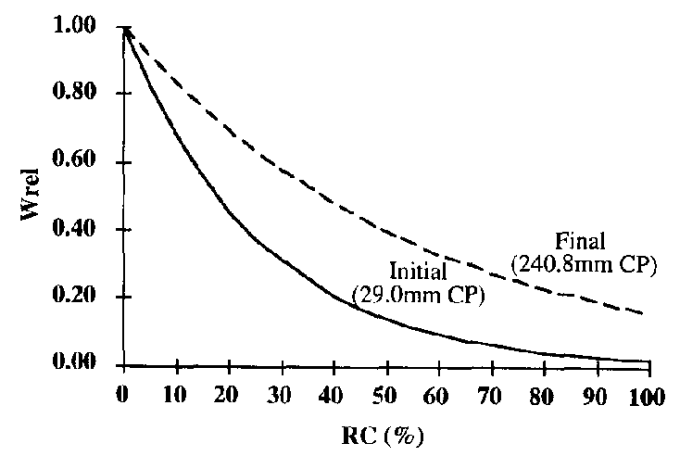

Fig. 6. Effect of cumulative precipitation $(\mathrm{CP}, \mathrm{mm})$ on the relationship between wash (Wrel) and rock cover ( $\mathrm{RC}, \%)$. Wash is expressed in relative values (Wrel-treatment wash/bare soil wash) (rectangular, medium size, resting on top soil rock fragments).

gression coefficient values $(b)$ were higher than for the general relationship ( $b=0.0281$, Eq. (4)). These $b$ values can be considered statistically similar, especially for the two first events, preceding $80 \mathrm{~mm}$ of cumulative precipitation. The last two events corresponded to significantly lower $b$ values (Table 5).

As shown also by values in Table 5, for events 1 through 3, the values of $b$ in the linear relationship between splash and RC remained higher than 0.01 . For the rest of the experiment, these values were under 0.007 . Yet, no significant differences between $b$ values were found.

Regression analysis was applied to assess the effect of cumulative precipitation $(\mathrm{CP})$ on $b$ values,

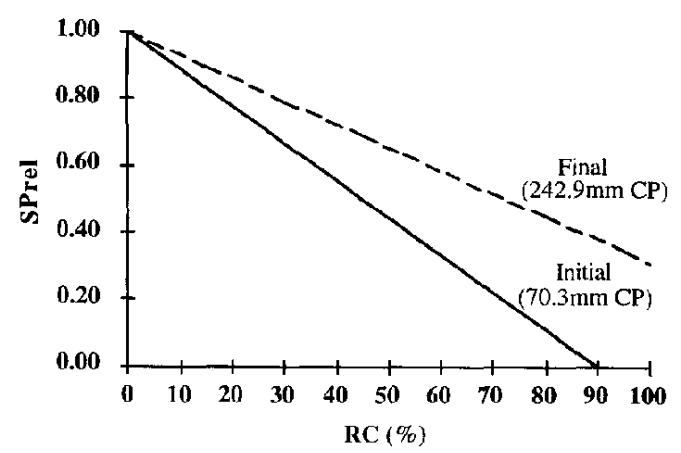

Fig. 7. Effect of cumulative precipitation $(\mathrm{CP}, \mathrm{mm})$ on the relationship between splash (SPrel) and rock cover (RC, \%). Splash is expressed in relative values (SPrel--treatment splash/bare soil splash) (rectangular, medium size, resting on top soil rock fragments). 


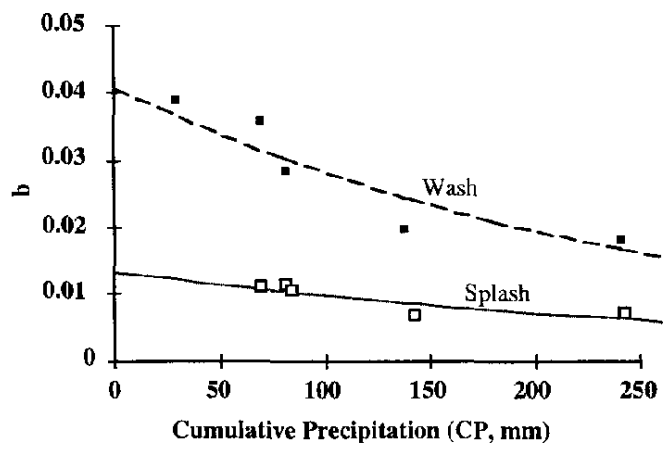

Fig. 8. Effect of cumulative precipitation on regression coefficients $(b)$ of the relationships between wash and splash, and rock cover (Eqs. (7) and (8)). Wash and splash are expressed in relative values (treatment/bare soil) (rectangular, medium size, resting on top soil rock fragments).

either for wash or for splash. For wash, logarithmic and exponential regression functions were tested (Eqs. (6) and (7)).

$$
\begin{aligned}
b & =0.0772-0.0109 \ln (\mathrm{CP}+1) \\
n & =5 \quad r=0.936^{* *} \\
b & =0.0409 \exp (-0.0037 \mathrm{CP}) \quad n=5 \quad r=0.911^{*} \text { * }
\end{aligned}
$$

In the logarithmic fit, input values of cumulative precipitation were summed to 1 , in order to allow for a more realistic value for the intercept of the function. Notwithstanding, the better correlation coefficient, the logarithmic regression function yields a too high value of $b$ at the beginning of the experiment, when compared with that obtained with the exponential fit. As the output for time zero is more realistic, Eq. (7) thus, seems to represent the situation better (Fig. 8).

An exponential relationship between $b$ and $\mathrm{CP}$ also fitted the splash data (Fig. 8):

$$
b=0.0133 \exp (-0.0031 \mathrm{CP}) \quad n=5 \quad r=0.857^{*}
$$

A recent review of literature concerning the relationship between interrill erosion and rock cover (Poesen et al., 1994) indicates that $b$ values, obtained from data of various sources, fall in the range of 0.060 to 0.020 . As shown by our data, $b$ values vary with time, and cumulative rainfall is the main factor controlling this variation. Therefore, this con-

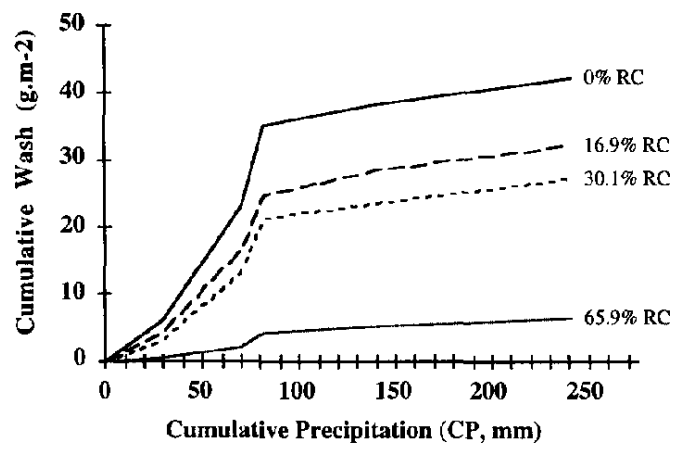

Fig. 9. Evolution of cumulative wash with cumulative precipitation for the tested rock cover percentages (RC, \%) (rectangular, medium size, resting on top soil rock fragments).

trolling factor might explain differences in $b$ values found in different experiments or under different conditions.

The temporal evolution of wash and splash during the experiment showed the above mentioned sharp decrease after about $80 \mathrm{~mm}$ of cumulative precipitation. In Figs. 9 and 10, where cumulative soil loss is plotted against cumulative precipitation, this decrease is clearly shown. The threshold of $80 \mathrm{~mm}$ of cumulative precipitation corresponded to the last early summer rainfalls, which almost ceased later in this season. The first rainfalls in autumn generated much lower wash and splash values in all treatments.

The temporal variation of wash and also of splash was caused by the formation of a surface seal. The seal, easily observed during the experiment, reduced particle availability for overland flow transport.

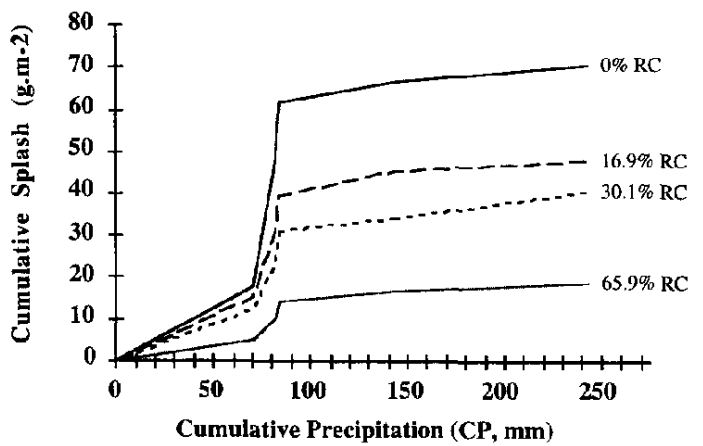

Fig. 10. Evolution of cumulative splash with cumulative precipitation for the tested rock cover percentages (RC,\%) (rectangular, medium size, resting on top soil rock fragments). 
Hence, with time, the erosional process was more and more detachment limited. This situation was also identified at the plot scale in the Douro Region vineyards (de Figueiredo and Ferreira, 1993). The effect of a permanent near saturation situation in soil did not limit the crust formation and stabilization after about $80 \mathrm{~mm}$ rainfall. This finding does not agree with the experimental evidence reported by Le Bissonnais and Singer (1992), who found no crust formation after $120 \mathrm{~mm}$ rainfall in a saturated soil. No splash compensation was provided in the experimental design, thus, the relative concentration of coarser and compacted particles in soil surface may have been enhanced as the finer ones irreversibly left the plot box.

\section{Conclusion}

Total infiltration depth followed a positive relationship with rock fragment cover (RC) when rock fragments rested on top of the soil surface. This result agrees with those cited in literature. The negative effect of RC on runoff volume, also reported in the literature, was not so consistent as that found for infiltration. For bare soil, the global volume of water splashed out of the simulated interrill area represented about one third of the total rainfall and did not significantly vary with $\mathrm{RC}$.

The global effect of $\mathrm{RC}$ on wash was well described by a negative exponential function. The coefficient of this function, i.e., $b=0.0281$, was among the lower values found in literature. Global values of splash loss varied negatively with RC. According to the linear regression function fitted to data, splash ceased at a rock fragment cover of $88 \%$.

The relationships between soil loss (wash and splash) and RC varied during the experiment. Cumulative precipitation, a factor controlling this variation, negatively affected the regression coefficients of the functions fitted to wash (exponential) and splash (linear) data. As there is no single relationship between interrill soil loss and rock cover, a time scale should be considered when quantifying this relationship. This implies, for instance, that data from short term experiments should not be used to assess long term effects of rock fragment cover on interrill soil loss.
The effects of rock fragment characteristics, for the conditions tested, were less significant compared to that of RC. Rock fragments size was the most important factor, followed by rock fragments position (embedded or resting on top of soil surface). Shape of rock fragments had no significant effect on global results. Size of rock fragments positively affected splash, wash and runoff and, on the contrary, negatively affected infiltration.

\section{Acknowledgements}

The authors gratefully acknowledge the collaboration and help of M. Mário Graça and the technical staff of the Soil Science Laboratory at the Escola Superior Agrária de Bragança, who were essential for the installation in time and monitoring of the experimental setup. Financial support by the European Commission through the MEDALUS project (Environment and Climate Research Programme, contract ENV4-CT95-0118, Climatology and Natural Hazards) is acknowledged. Authors also acknowledge two anonymous referees, whose comments were very helpful to improve the manuscript.

\section{References}

Agroconsultores e Coba, 1991. Carta dos Solos, Carta do Uso Actual da Terra e Carta da Aptidão da Terra do Nordeste de Portugal. Universidade de Trás-os-Montes e Alto Douro, Vila Real, Portugal.

Baird, A.J., Thornes, J.B., Watts, G.P., 1992. Extending overland-flow models to problems of slope evolution and the representation of complex slope-surface topographies. In: Parsons, A.J., Abrahams, A.D. (Eds.), Overland Flow: Hydraulics and Erosion Mechanics, Chapman \& Hall, New York, pp. 199-223.

Le Bissonnais, Y., Singer, M.J., 1992. Crusting, runoff and erosion response to soil water content and successive rainfalls. Soil Sci. Society Am. J. 56, 1898-1903.

Box, 1981

FAO/UNESCO, 1988. Soil Map of the World. Revised Legend, FAO, Rome, Italy.

de Figueiredo, T., Ferreira, A.G., 1993. Erosão dos solos em vinha de encosta na região do Douro, Portugal. Actas do XII Congresso Latinoamericano da Ciência do Solo, SECS, 19-26 September 1993, Salamanca, Spain, pp. 79-88.

Free, G., 1952. Soil movement by raindrops. Agric. Eng., 33, 491-494, 496 
Gras, R., 1994. Sols caillouteux et production végétale. INRA, Paris.

Lane, L.J., Nearing, M.A. (Eds.), 1989. Water Erosion Prediction Project: Hillslope Profile Documentation. National Soil Erosion Research Laboratory Report 2, W. Lafayette, IN.

Lavee, H., Poesen, J., 1991. Overland flow generation and continuity on stone-covered soil surfaces. Hydrol. Processes 5, 345-360.

de Lima, M.I.P., 1990. Laboratory experiments on water erosion of stony soils. Proceedings of the Seminar on Interaction between Agricultural Systems and Soil Conservation in the Mediterranean Belt, ESSC, Oeiras, Portugal.

Meyer et al., 1972.

Morgan, R.P.C., Quinton, J.N., Rickson, R.J., 1993. EUROSEM: A User Guide. Silsoe College, UK.

Poesen, J.W.A., 1990. Erosion processes research in relation to soil erodibility and some implications for improving soil quality. In: Albaladejo, J., Stocking, M.A., Diaz, E. (Eds.), Soil Degradation and Rehabilitation in Mediterranean Environmental Conditions. CSIC, Murcia, Spain, pp. 159-170.

Poesen, J., 1992. Mechanisms of overland flow generation and sediment production on loamy and sandy soils with and without rock fragments. In: Parsons, A.J., Abrahams, A.D. (Eds.), Overland Flow: Hydraulics and Erosion Mechanics. Chapman \& Hall, New York, pp. 275-306.

Poesen, J., Ingelmo-Sanchez, F., 1992. Runoff and sediment yield from topsoils with different porosity as affected by rock fragment cover and position. Catena 19, 451-474.

Poesen, J., Lavee, H., 1991. Effects of size and incorporation of synthetic mulch on runoff and scdiment yield from interrills in a laboratory study with simulated rainfall. Soil Tillage Res. 21, 209-223.

Poesen, J., Lavee, H. (Eds.), 1994. Rock Fragments in Soil: Surface Dynamics. Catena, 23 (1-2), 198 pp.
Poesen, J., Savat, J., 1981. Detachment and transportation of loose sediments by raindrop splash: Part II. Detachability and transportability measurements. Catena 8, 19-41.

Poesen, J., Torri, D., 1988. The effect of cup size on splash detachment and transport measurements: Part I. Field measurements. Catena Suppl. 12, 113-126.

Poesen, J., Ingelmo-Sanchez, F., Mucher, H., 1990. The hydrological response of soil surfaces to rainfall as affected by cover and position of rock fragments in the top layer. Earth Surface Processes Landforms 15, 653-671.

Poesen, J., Torri, D., Bunte, K., 1994. Eiffects of rock fragments on soil erosion by water at different spatial scales: a review. In: Poesen, J., Lavee, H. (Eds.), Rock Fragments in Soil: Surface Dynamics. Catena, 23, pp. 141-166.

Renard, K.G., Foster, G.R., Weesies, G.A., McCool, D.K., Yoder, D.C. (coord.), 1992. Predicting Soil Erosion by Water: A Guide to Conservation Planning with the Revised Universal Soil Loss Equation (RUSLE). USDA, Washington, DC.

Savat, J., Poesen, J., 1981. Detachment and transportation of loose sediments by raindrop splash: Part I. The calculation of absolute data on detachability and transportability. Catena 8, 1-17.

Simanthon et al., 1984.

Steel, R.G.D., Torrie, J.H., 1980. Principles and Procedures of Statistics, 2nd edn., McGraw-Hill, Tokyo, Japan.

van Wesemael, B., Poesen, J., de Figueiredo, T., 1994. Effects of rock fragments on physical degradation of cultivated soils by rainfall. Soil Tillage Res. 33, 229-250.

van Wesemael, B., Poesen, J., de Figueiredo, T., Govers, G., 1996. Surface roughness evolution of soils containing rock fragments. Earth Surface Processes Landforms 21, 399-411.

Wischmeier, W.H., Smith, D.D., 1978. Predicting rainfall erosion losses-a guide to conservation planning. USDA, Washington, DC. 